\title{
The Adequacy and Acceptability of Machine Translation in Translating the Islamic Texts
}

\author{
Atef Odeh AbuSa'aleek ${ }^{1}$ \\ ${ }^{1}$ Department of English language and Translation, Unaizah Community College, Qassim University, Saudi \\ Arabia \\ Correspondence: Atef Odeh AbuSa'aleek, Department of English language and Translation, Unaizah Community \\ College, Qassim University, Saudi Arabia. E-mail: atefodeh@hotmail.com
}

Received: April 11, 2016 Accepted: April 30, 2016 Online Published: May 25, 2016

doi:10.5539/ijel.v6n3p185 URL: http://dx.doi.org/10.5539/ijel.v6n3p185

\begin{abstract}
Islamic translation is considered as a special distinguished sub-discipline of applied linguistics. It is one of the most important areas of translation because it carries the values and eternal message. Through the history, the first translation work was of religious books. This study attempts to evaluate the adequacy and acceptability of four machine translation (MT) systems (World lingo, Babylon translation, Google translate, Bing translator) in translating the Islamic texts. In addition, it aims to evaluate the Islamic translation outputs based on functional characteristics (accuracy, suitability, and well-formedness) and sub-characteristics (syntax, terminology, reliability, and fidelity). The findings indicted that Google Translate System is the most adequate and acceptable among the other three systems (World lingo, Babylon translation, Bing translator) in translating the Islamic texts. The findings also revealed that Google Translate is acceptable in producing Islamic translation outputs in regard to the following functional characteristics (accuracy, suitability, and well-formedness) and sub-characteristics (syntax, terminology, reliability and fidelity) due to Google Translate advancement.
\end{abstract}

Keywords: adequacy of machine translation systems, Islamic translation, Arabic into English translation

\section{Introduction}

The emergence of Machine Translation (MT) has a significant role in translating the Arabic texts in particular because human translation cannot handle huge amounts of texts that need to be transferred to other languages.

Recently, the evaluation methods play an extremely significant role in the advancement of computer-mediated translation systems. With the emergence of Islamic English, there is a need to attain an exact Arabic into English MT production. Machine Translation is taking new dimensions, mainly in getting an accurate output, especially in Arabic into English MT.

Machine translation refers to transfer text from one language to another by using software. Daniel \& Martin, (2009) defined MT as an automatic process of transferring text from one human language to the target language by using context information.

Gerber (2012, p. 7) support the above idea "the goal of the translation process is to take Arabic source text drawn from many different genres, both spoken and written, and translate it into fluent English while preserving all of the meaning present in the original Arabic text. Translation agencies will use their own best practices to produce high quality translations. While we trust that each agency has its own mechanism of quality control, we provide the following specific guidelines so that all translations are guided by some common principles".

Studies in recent years have shown expansion of interest in investigating the evaluation of machine mainly in Arabic into English MT. (Abu-Al-Sha'r \& AbuSeileek, 2013; Hebresha \& Ab Aziz, 2013; Gerber, 2012; Marcu et al., 2012; Huck, Stein, \& Ney, 2011; Abu-Al-Sha'r, 2009; Galley et al., 2009; Attia, 2008; Salem et al., 2008; Habash, 2007; and Al-Otoum, 2006).

Al-Sha'r \& AbuSeileek (2013, p. 526) supported the above mentioned idea "the main concern of translation from Arabic into English researchers is exploring a matric that improves accurate syntactic transformation. Their efforts have some success and have now gained popularity as a research pursuit. In addition, other researchers' efforts in MT have also paved the road for research concerned with empirical methods in natural language processing". 
Islamic translation is considered as a special distinguished sub-discipline of applied linguistics. It has its own characteristics. The translator should know its skills and its issues. Islamic Translation is one of the most important areas of translation because it carries the values and eternal message. Through of the history, we can find that the first translation work was of religious books of the Torah, the Bible, and the Quran. Therefore, there is a demand to evaluate the adequacy and acceptability of free MT system in translating the Islamic texts. For drawing such evaluation, a comparative analysis of Islamic translated texts will be conducted according to specific criteria concentrating on the characteristics of the outcome quality: syntax, terminology, reliability and fidelity. The development in the area of MT from Arabic into English is manifest to be important due to getting a relatively correct translation of Arabic text. Even though a number of Arabic MT systems have somewhat attain a satisfactory level of output translation, the level of transferring exact data from a source language into target language requires additional processing by approximately all MT systems.

\subsection{Research Problem}

Research work conducted in Arabic into English Machine translation system is very important in the field of Translation. Hence, there are few studies conducted in evaluation of Arabic-English MT system.

In addition, there is a need to conduct research on evaluation of the adequacy and acceptability of Arabic-English MT systems in translating the Islamic texts due to the huge and size of Arabic Islamic text to be translated in the recent years. The previously conducted studies focused on analysis variety of literary, economic, legal, journalistic and technical texts but not Islamic texts. According to the best knowledge of the researcher, there is no research conducted regard adequacy and acceptability of Arabic-English MT systems in translating the Islamic texts

\subsection{Significance of the Study}

Previous studies of MT have been conducted with a view investigating the efficiency of MT systems, output evaluation of Arabic into English MT in translating literary, technical and legal text, problems of Arabic MT, and morphological and syntactic representation in MT. However, this study is unlike the above-mentioned studies. This study focuses on evaluation the adequacy and acceptability of four MT systems (World lingo, Babylon translation, Google translate, Bing translator) in translating the Islamic texts. In addition, it aims to evaluate the Islamic translation output based on functional characteristics (accuracy, suitability, and well-formedness) and sub-characteristics (syntax, terminology, reliability and fidelity). Furthermore, this study is significant because it is a serious attempt at getting a better understanding of the effectiveness of MT in translating the Islamic texts and it is beneficial for translators, students, educators and scholars in the field of translation.

\section{Review of Literature}

The evaluation of MT systems is an important area of exploring, together for determining the Adequacy, the acceptability of current MT systems and quality of the output of MT systems. Evaluation of MT output has been shown in many studies see Abu-Al-Sha'r \& AbuSeileek, 2013; Hebresha \& Ab Aziz, 2013; Carpuat et al., 2010; Gerber, 2012; Marcu et al., 2012; Huck, Stein, \& Ney, 2011; Abu-Al-Sha'r, 2009; Galley et al., 2009; Attia, 2008; Salem et al., 2008; Habash, 2007; and Al-Otoum, 2006.

Recently, the evaluation process of MT has an extremely significant role in the development of advancement of MT systems. Abu-Al-Sha'r \& AbuSeileek (2013) investigated the advancements of MT systems between 2008 and 2013. The researchers evaluate seven MT systems by making a comparative analysis and re-evaluation of the texts according to certain criteria to evaluate the output. The corpus of analysis contains a variety of literary, economic, legal, journalistic and technical texts. The findings indicate that there was some advancement in the characteristics output of Google MT system in comparison with other six MT systems.

Hebresha \& Ab Aziz (2013) conducted a study to design an automatic translation system to translate Classical Arabic texts into English based on Rule-based approach. Arabic MT system includes analysis, transfer and generation stages. A comparative evaluation conducted between MT system output and human translation output for tracing the effectiveness of Arabic automatic translation system. The result of the evaluation indicates that $89.4 \%$ is the accuracy of the output, which demonstrates that utilizing Rule-based approach afford good output in translating the classical Arabic into English.

Huck, Stein, \& Ney (2011) conducted a study entitled "Advancements in Arabic-to- English Hierarchical Machine Translation". They investigated a number of advanced method and model in statistical MT form Arabic into English. They focus on the framework of hierarchical phrase-based translation. They gathered complementary techniques that were examined in isolation and mainly on different pairs of language. The combination of the techniques and models yield noteworthy advancement over a baseline utilizing a normal set 
of models. The outcome hierarchical systems present competitive on the large-scale of National Institute of Standards and Technology Arabic into English translation job.

Shenassa \& Khalvandi (2008) designed an evaluation system to analyze the different English translations output of the Quran by using computational linguistic.

Abu-Al-Sha'r \& AbuSeileek (2013, p. 527) state that "Translation from Arabic into English is a complex and demanding process where productivity could be determined by the quality and range of its dictionary". Al-Otoum (2006) conducted a study to evaluated Arabic into English MT systems: namely Tran Sphere, and An-nakel. He examined the overall quality of translation resulted by these two MT systems concerning the four functional criteria: readability, fidelity, terminology, and syntax. The results indicated that the output of both systems contains low faithfulness, language problems, a mistranslation of terms, and inadequacy.

Izwaini (2006) evaluated three Arabic-English MT systems to identify the problems of Arabic MT, its causes, and solutions. MT namely Google, Sakhr, \& Systran is investigated to recognize a variety of frequent linguistic problems. The findings illustrate that the output of the three MT has two deficiencies in Google MT concerning the writing format. Sakhr MT has better output due to the diacritics in its system. Systran MT provides literal translation output, problems in grammar, word order, and many items remain as it is. The output of Systran's distorted language.

\section{Research Methodology}

The present section deals with designing of research methodology of the study. It presents the objectives and the questions of the study. Furthermore, it describes in detail the corpora under investigation and research instrument.

\subsection{Objectives of the Study}

This study attempts to evaluate the adequacy and acceptability of four MT systems (World lingo, Babylon translation, Google translate, Bing translator) in translating Islamic texts. In addition, it aims to evaluate the Islamic translation output based on functional characteristics (accuracy, suitability, and well-formedness) and sub-characteristics (syntax, terminology, reliability and fidelity). Adequacy refers to the quality and correctness of the output translation, whereas acceptability refers to the linguistic appropriateness of the MT output.

\subsection{Questions of the Study}

1) Are there any statistically significant differences between MT systems (World lingo, Babylon translation, Google translate, Bing translator) in translating the Islamic texts?

2) Are there any statistically significant differences in Islamic translation output based on functional characteristics (accuracy, suitability, and well-formedness) and sub-characteristics (syntax, terminology, reliability, and fidelity)?

\subsection{Corpora}

The corpora used in this research consist of five Islamic text-genres covered supplication, part of a sermon, pillars of Islam, Hadith (sayings of the prophet of Islam) from Arabic into English using four Machine Translation: World lingo, Babylon translation, Google translate, Bing translator.

This study proposes to evaluate the four functional characteristics syntax, terminology, readability, and fidelity. The Islamic texts will be translated via four MT systems (Google translate, Bing translator, Babylon translation, World lingo). Different scales will be applied in this evaluation. A panel of three specialist referees in translation had Ph.D. in applied linguistics evaluated the MT outputs. They translated $10 \%$ of the sample outputs together. Furthermore, they discussed points of differences until the agreement was reached. Then they assessed the output texts individually. The inter-rate reliability between them was calculated. It was found 0.85 , which is statistically accepted for the purposes of this study. For the total translation, it was found that 0.84 for fidelity, 0.89 for syntax, 0.86 for terminology and 0.81 for readability.

To evaluate readability and fidelity, a measurement of a 4-point scale ( 0 to 3 ) will be used. Where 0 shows the lowest result while 3 shows the clarity of the meaning in spite of the incidence of other mistakes, will be applied to recognize whether the output of the Islamic texts is exactly transferred by the four MT systems. To measure the syntax of the output texts 5-point scale will be used. To evaluate the terminology measurement of a 2-point scale will be used to verify whether the translation is accurate. After that, the overall marks will be organized in accord to the most reliable findings of the output on each matrix. 


\section{Findings of the Study}

The following section deals with findings of the study under the following subtitles, readability of selected sample of Islamic texts by four MT systems, the fidelity of selected sample of Islamic texts by four MT systems, the syntax of selected sample of Islamic texts by four MT systems and the overall evaluation of the four MT systems.

\subsection{Readability of Selected Sample of Islamic Texts by Four MT Systems}

Table 1 below presents the mean score measurement of readability of 30 statements under study by the four MT systems. To measure the readability the researcher applies a 4-point scale from 0 to 3 . This scale measures to what extent the SL text is accurately transferred into TL text. Hence, 0 is the lowest score and 3 is the highest score. However, (3) shows that the meaning is correctly conveyed, clear, and acceptable from the first reading; (2) shows that the meaning of the outputs translation seems clear with some justification; whereas (1) indicates that the meaning is below $50 \%$ of being understood, and $(0)$ shows that the meaning is completely unclear.

The findings in Table 1 indicate that the overall evaluation of readability in the four MT systems shows that Google Translate system has gained a high level of clarity in transferring the texts from Arabic into English $(80 \%)$ and its output is more acceptable than the other MT systems. Whereas the means of readability in the outputs of Bing Translator system is (63.3\%) which also seems acceptable, the means of readability in the outputs of Babylon Translator system is (53.3) and the World lingo Translator system is the least acceptable with $(13.3 \%)$ means of readability. It should be noted that (3) and (2) on the scale show the positive points.

Table 1 . The mean of the outputs scores regard readability

\begin{tabular}{lllll}
\hline Readability scale & Google Translate & Bing Translator & Babylon Translator & World lingo Translator \\
\hline 0 & 16.7 & 20 & 20 & 53.3 \\
1 & 3.3 & 16.7 & 26.7 & 33.3 \\
2 & 36.7 & 40 & 30 & 10 \\
3 & 43.3 & 23.3 & 23.3 & 3.3 \\
Total & 100 & 100 & 100 & 100 \\
\hline
\end{tabular}

\subsection{Fidelity of Selected Sample of Islamic Texts by four MT Systems}

Table 2 below illustrates the mean score measurement of fidelity of 30 statements under study by the four MT systems. To measure the fidelity the researcher applies 4-point scale from 0 to 3 . This scale to measure to what extent the information of the 30 statements transferred completely and faithfully. Hence, 0 is the lowest score and 3 is the highest score. However, (3) shows that almost all the information is faithfully conveyed from the first reading; (2) shows that the information is relatively faithful; whereas (1) indicates that the percentage of faithfulness in transferring the information is below $50 \%$; and (0) indicates that the information is not translated faithfully.

The findings in table 2 demonstrate that Google Translate System has achieved a high level of faithfulness in transferring the Islamic texts (73.4\%) compared with the other three MT systems. These systems were Bing translator, Babylon translator, World lingo translator were below $(50 \%)$ which produce unfaithfully translation.

Table 2. The mean of the outputs scores regard fidelity

\begin{tabular}{lllll}
\hline Fidelity scale & Google Translate & Bing Translator & Babylon Translator & World lingo Translator \\
\hline 0 & 20 & 23.3 & 30 & 60 \\
1 & 6.6 & 36.7 & 30 & 33.3 \\
2 & 36.7 & 26.7 & 33.3 & 3.3 \\
3 & 36.7 & 13.3 & 6.7 & 3.3 \\
Total & 100 & 100 & 100 & 100 \\
\hline
\end{tabular}

\subsection{Syntax of Selected Sample of Islamic Texts by Four MT Systems}

Table 3 below illustrates the mean score measurement of the syntax of 30 statements under study by the four MT systems. To measure syntax that contains all the grammatical problems. The researcher used a 5-point scale from 1 to 5 . This scale is to measure the grammatical correctness of the statements. Where, 1 is the lowest score and 5 is the highest score. However, (5) shows that the statement is grammatically perfect; (4) indicates that the 
statement is almost perfect but with few minor problems. (3) Shows that the statement is reasonably grammatical, but has less serious problems; (2) indicate that the statement is almost ungrammatical, but has many serious problems that affect the meaning; and (1) shows that the statement is fully ungrammatical fragment.

Table 3 indicates that the outputs translation of Google translate system has the least grammatical problems compared to the other MT systems. Google Translate System has achieved very high percentage compared with the other systems that are Bing translator, Babylon translation, World lingo.

Table 3. The mean of the outputs scores regards to syntax

\begin{tabular}{lllll}
\hline Syntax scale & Google Translate & Bing Translator & Babylon Translator & World lingo Translator \\
\hline 1 & 3.33 & 13.33 & 10 & 36.66 \\
2 & 13.33 & 13.33 & 20 & 20 \\
3 & 6.66 & 40 & 26.66 & 26.66 \\
4 & 30 & 20 & 30 & 13.33 \\
5 & 46.66 & 13.33 & 13.33 & 3.33 \\
Total & 100 & 100 & 100 & 100 \\
\hline
\end{tabular}

\subsection{Terminology of Selected Sample of Islamic Texts by Four MT Systems}

Table 4 below presents the mean score measurement of terminology of the 30 statements under study by the four MT systems. To measure terminology that proves the accuracy of the translation. The researcher used a 2-point scale from 0 to 1 . This scale is to decide whether the translation is correct or not.

Where (0) is assigned to the terms that are wrongly translated, but (1) indicates that the terms are correctly translated. The means of the outputs translation of Google translate system (83.3\%) and Bing Translator system $(60 \%)$ has gone beyond the level of 50\%, which proves that Google translate system generate an accurate choice of terms equivalent to the Islamic translated text. Findings also revealed that the means of terminology of Babylon translator system is 46.7 but the World lingo Translator System has mistranslated majority of terms.

Table 4. The mean of the outputs scores with regard to terminology

\begin{tabular}{lllll}
\hline Scale of Terminology & Google Translate & Bing Translator & Babylon Translator & World lingo Translator \\
\hline 0 & 16.7 & 40 & 53.3 & 73.3 \\
1 & 83.3 & 60 & 46.7 & 26.7 \\
Total & 100 & 100 & 100 & 100 \\
\hline
\end{tabular}

\subsection{The Overall Evaluation of the Four MT Systems}

To evaluate the outputs of the four MT systems, the percentages of the means of the four scales (readability, fidelity, syntax, and terminology) were calculated. Table 5 presents the means of the evaluation of the Islamic texts translated by the four systems. The findings indicate that Google translate system has achieved the highest performance in readability, fidelity, syntax, and terminology. Table 5 also shows that the percentages of fidelity and syntax are below 50\% for Babylon Translator system and World lingo Translator system; whereas the percentage of readability and terminology is higher than $50 \%$ for Google Translate System and Bing Translator system.

Table 5. Overall evaluations of Sub-functional characteristics (100\%)

\begin{tabular}{|c|c|c|c|c|}
\hline \multirow{3}{*}{ MT System } & \multicolumn{4}{|c|}{ Sub-functional characteristics (100\%) } \\
\hline & Readability & Fidelity & Syntax & Terminology \\
\hline & $\%$ & $\%$ & $\%$ & $\%$ \\
\hline Google Translate & 80 & 73.4 & 76.66 & 83.3 \\
\hline Bing Translator & 63.3 & 40 & 33.33 & 60 \\
\hline Babylon Translator & 53.3 & 40 & 43.33 & 46.7 \\
\hline World lingo Translator & 13.3 & 6.6 & 16.66 & 26.7 \\
\hline
\end{tabular}

Table 6 presents the means of each functional sub-characteristic of the four MT systems. The means in Table 6 shows the percentage of each sub-characteristic out of (25\%). 
The findings indicate that Google translate system has achieved the highest percentage in readability, fidelity, syntax, and terminology. Table 5 also indicates that the percentages of readability, fidelity, syntax, and terminology are below 50\% for Bing Translator System, Babylon Translator system and World lingo Translator system.

Table 6. Overall evaluations of Sub-functional characteristics ( $25 \%$ each)

\begin{tabular}{|c|c|c|c|c|c|}
\hline \multirow{3}{*}{ MT System } & \multicolumn{5}{|c|}{ Sub-functional characteristics ( $25 \%$ each) } \\
\hline & Readability & Fidelity & Syntax & Terminology & Total \\
\hline & $\%$ & $\%$ & $\%$ & $\%$ & $100 \%$ \\
\hline Google Translate & 20 & 18.35 & 19.17 & 20.82 & 78.34 \\
\hline Bing Translator & 15.8 & 10 & 8.33 & 15 & 49.13 \\
\hline Babylon Translator & 13.3 & 10 & 10.83 & 11.67 & 45.8 \\
\hline World lingo Translator & 3.3 & 1.65 & 4.17 & 6.67 & 15.79 \\
\hline
\end{tabular}

Table 7 presents the percentages of the functional characteristics of the General Software Quality (GSQ). These functional characteristics constitute $100 \%$, which is divided into three criteria: suitability with (25\%), accuracy, $(50 \%)$ and well-formedness with $(25 \%)$.

The percentages of each criterion: readability, fidelity, syntax, and terminology are calculated in terms of suitability, accuracy, and well-formedness. Hence, readability stands for suitability and has the percentage of $(25 \%)$, accuracy represents both fidelity and terminology and has (50\%), and well-formedness represents syntax which has $(25 \%)$

The overall percentages of suitability, accuracy, and well-formedness show that Google Translate System is the most adequate and acceptable among the other three systems taking into account the criteria of readability, terminology, fidelity, and syntax. Google translator System has achieved the highest percentage (78.34\%), followed by Bing Translator System, Babylon Translator system and World lingo Translator system, which is below $50 \%$.

Table 7. The percentages of each criterion in the General Software Quality (GSQ)

\begin{tabular}{lllll}
\hline \multirow{3}{*}{ MT System } & \multicolumn{4}{l}{ Sub-functional characteristics (100\%) } \\
\cline { 2 - 5 } & $\begin{array}{l}\text { Suitability } \\
(25 \%)\end{array}$ & $\begin{array}{l}\text { Accuracy } \\
(50 \%)\end{array}$ & Well- formedness & $\begin{array}{l}\text { Total } \\
(100 \%)\end{array}$ \\
\cline { 2 - 5 } Google Translate & 20 & 39.17 & 19.17 & 78.34 \\
Bing Translator & 15.8 & 25 & 8.33 & 49.13 \\
Babylon Translator & 13.3 & 21.67 & 10.83 & 45.8 \\
World lingo Translator & 3.3 & 8.32 & 4.17 & 15.79 \\
\hline
\end{tabular}

\section{Discussion, Conclusion \& Recommendations}

The discussion of the results is presented in two sections. First presents the discussion related to the first question whether there are statistically significant differences between MT systems (World lingo, Babylon translation, Google translate, Bing translator) in translating the Islamic texts. The second is the discussion devoted to the second question whether there are any statistically significant differences in Islamic translation output based on functional characteristics (accuracy, suitability, and well-formedness) and sub-characteristics (syntax, terminology, reliability and fidelity).

By comparing the mean scores of outputs translation of the four MT systems (World lingo, Babylon translation, Google Translate Service, Bing translator) in translating the Islamic texts. The findings revealed that Google Translate System is the most adequate and acceptable among the other three systems in translating the Islamic texts as seen in the tables above.

The findings regard the second question indicated that Google Translate System has achieved very high percentage in terms of four sub-functional characteristics: readability is $20 \%$; fidelity is $18.35 \%$; syntax is $19.17 \%$; and terminology is $20.82 \%$ compared with the other systems that are Bing translator, Babylon translation, World lingo. Bing translator comes second where readability got the higher percentage (15.8) among the other three standards. Tables 5 and 6 illustrate the means of the overall evaluation of the seven MT systems according to the four scales: readability, fidelity, syntax, and terminology. Each standard stands for $25 \%$ of the 
GSQ (General Software Quality) which is $100 \%$. Table 7 shows overall percentages of suitability, accuracy, and well-formedness of the output translation. The findings: suitability is $20 \%$, accuracy is 39.17 out of 50 , and well-formedness 19.17; with the total (78.34\%) show that Google Translate System is the most adequate and acceptable among the other three systems. Followed by Bing Translator System, Babylon Translator system and World lingo Translator system, which is below $50 \%$. The findings of this study are also in accord with the findings reported by the earlier studies regarding the effectiveness of MT systems (see, for instance, Abu-Al-Sha'r \& AbuSeileek, 2013; Arabglot, 2012; Abu Alsha'r, 2008). These findings clarify that why some translation outputs are unintelligible, indecipherable, unfaithful, and inaccurate. Abu-Al-Sha'r \& AbuSeileek (2013, p. 534) state that "Google Translate can make intelligent guesses as to what an appropriate translation should be. In addition, the alternatives suggested by Google gear the focus towards the urgent need to a perfect transfer of the translation output in the present time".

Another explanation, which supports this result according to Google (2016), is that "When Google Translate generates a translation; it looks for patterns in hundreds of millions of documents to help decide on the best translation for you. By detecting patterns in documents that have already been translated by human translators, Google Translate can make intelligent guesses as to what an appropriate translation should be. This process of seeking patterns in large amounts of text is called "statistical machine translation". Since the translations are generated by machines, not all translation will be perfect. The more human-translated documents that Google Translate can analyse in a specific language, the better the translation quality will be. This is why translation accuracy will sometimes vary across languages."

To sum up, Google Translate System is the most adequate and acceptable among the other three systems (World lingo, Babylon translation, Bing translator) in translating the Islamic texts. The finding of the present study also indicates that Google Translate is acceptable in producing Islamic translation output in regard to the following functional characteristics (accuracy, suitability, and well-formedness) and sub-characteristics (syntax, terminology, reliability and fidelity) due to Google Translate advancement. Abu-Al-Sha'r \& AbuSeileek (2013) support these findings by stating that Google Translate advancement in producing satisfactory Arabic translation has exceeded expectations, due to the better understanding of the unique characteristics of Arabic language and adopting and applying the most suitable processing approaches.

The findings of the current study recommend that there is critical need for further research in this area to fill the gap in research. The researcher recommended conducting further studies with a larger number of Islamic texts to present a clear picture of the investigated phenomenon. Further studies and researches can be carried on to disprove or verify these findings. In addition, this paper is restricted only to four MT systems (World lingo, Babylon translation, Google translate, Bing translator). Further studies may be carried on to investigate other MT systems and linguistic features.

\section{Acknowledgment}

The author gratefully acknowledges Qassim University, represented by the Deanship of Scientific Research, on the material support for this research under the number (2997) during the academic year 1436 AH / 2015 AD.

\section{References}

Abu-Al-Sha'r, A. M. (2009). Output evaluation of available Arabic into English electronic Machine Translation systems. Translation Studies in the New Millennium, 7, 1-25.

Abu-Al-Sha'r, A. M., \& AbuSeileek, A. F. (2013). Advancement in productivity of Arabic into English Machine Translation Systems from 2008 to 2013. Educational Research and Reviews, 8(9), 525-538.

Al-Otoum, N. A. (2006). An evaluation of two Arabic into English Machine Translation systems: A comparative study. Yarmouk University, Jordan: Unpublished MA Thesis.

Attia, M. (2008). Handling Arabic morphological and syntactic ambiguity within the LFG framework with a view to Machine Translation. School of Languages, Linguistics and Cultures, the University of Manchester, UK.

Carpuat, M., Marton, Y., \& Habash, N. (2010). Improving Arabic-to-English statistical Machine Translation by reordering post-verbal subjects for alignment. Columbia University, Center for Computational Learning Systems. Proceedings of the ACL 2010 Conference Short Papers (pp. 178-183). Association for Computational Linguistics.

Carpuat, M., Marton, Y., \& Habash, N. (2010). Reordering matrix post-verbal subjects for Arabic-to-English SMT. In Proceedings of the Conference Traitement Automatique des Langues Naturelles (TALN). Cer D, 
Jurafsky D.

Daniel, J., \& Martin, J. H. (2009). Speech and language processing: An introduction to natural language processing, speech recognition, and computational linguistics. Englewood Cliffs, N: Prentice-Hall.

Galley, M., Green, S., Cer, D., Chang, P., \& Manning, Ch. (2009). Stanford University's Arabic-to-English Statistical Machine Translation System for the 2009 NIST evaluation. NIST 2009 Open Machine Translation Evaluation Workshop.

Gerber, L. (2012). Machine Translation: Ingredients for productive and stable MT deployments - Part 2. Retrieved from www.translationdirectory.com

Habash, N. (2007). Arabic Morphological representations for Machine Translation. In A. van den Bosch \& A. Soudi (Eds.), Arabic computational morphology knowledge-based and empirical methods. London: Springer. http://dx.doi.org/10.1007/978-1-4020-6046-5_14

Hebresha, H. A., \& AbAziz, M. J. (2013). Classical Arabic English Machine Translation Using Rule-based Approach. Journal of Applied Sciences, 13(1), 79. http://dx.doi.org/10.3923/jas.2013.79.86

Huck, M., Vilar, D., Stein, D., \& Ney, H. (2011). Advancements in Arabic-to- English Hierarchical Machine Translation. Proceedings of the 15th International Conference of the European Association for Machine Translation (pp. 30-31). Centre for Computational Linguistics, Katholieke Universiteit Leuven, Belgium.

Izwaini, S. (2006). Problems of Arabic Machine Translation: Evaluation of three systems. Proceedings of the International Conference on the Challenge of Arabic for NLP/MT (pp.118-148). The British Computer Society (BSC), London.

Marcu, D., Frazer, A., Wong, W., \& Knight, K. (2012). Language Weaver Arabic-English MT. Language Weaver, Inc.

Salem, Y., Hensman, A., \& Nolan, B. (2008). Towards Arabic to English Machine Translation. ITB J. 17, 1-17.

Shenassa, M. E., \& Khalvandi, M. J. (2008, April). Evaluation of different English translations of Holy Koran in scope of verb process type. In Information and Communication Technologies: From Theory to Applications, 2008. ICTTA 2008. 3rd International Conference on (pp. 1-4). IEEE. http://dx.doi.org/10.1109/ictta.2008.4530013

\section{Appendix A}

\section{The List of Machine Translation Websites}
A. http://www.worldlingo.com/
B. http://translation.babylon.com/
C. https://translate.google.com/
D. http://www.bing.com/translator/

\section{Appendix B}

\section{A Sample of Arabic Islamic Texts Followed by the Human Translation}

1) Brief Introduction about Islam

$$
\text { من الإسلام أن نؤمن بأن هذا الكون بما فيه له خالق هو الله وحده لا شريك له وهو المستحق للعبادة. }
$$

Human translation: Islam is to believe that this universe and what it contains have a Creator Who is Allah the One and the Unique. Allah does not have any partner and he deserves to be worshipped alone.

2) Part of sermon

$$
\text { الإسلام يأمر بالعدل و الإحسان والصلة و العفاف والصدق وجميع الصفات والأخلاق الطيبة. }
$$

Human translation: Islam commands to have mercy, kindness, integrity, close family relations, honesty and all the other good characters and manners.

3) First pillars of Islam

$$
\text { بُني الإسلام على خمس شهادة أن لا اله إلا الله وأن محمدأ رسول اله }
$$

Human translation: Islam has been built on five pillars: testifying that there is no God but Allah and that Muhammad is the Messenger of Allah. 
4) Hadith ( sayings of the prophet Muhammad peace be upon him)

$$
\text { قال النبي صل الله عليه وسلم “،اللهم إني ظلمت نفسي ظلما كثبر اولا يغفر الذنوب إلا أنت فاغفر لي مغفرة من عندك وارحمني إنك أنت الغفور }
$$

Human translation: Prophet Muhammad peace be upon him said that O God! I have wronged myself greatly, and none can forgive sins, except You only. Grant me forgiveness, and have mercy upon me; Surely, You are the Most Forgiver, Ever Merciful.

5) Supplication

$$
\text { رب أوز عني أن أثكر نعمتك التي أنعمت علي و على والدي وأن أعمل صالحا ترضاه و أدخلني برحمتك في عبادك الصالحين. }
$$

Human translation: "My Lord! Inspire and bestow upon me the power and ability that I may be grateful for Your Favours, which You have bestowed on me and on my parents, and that I may do righteous good deeds that will please You, and admit me by Your Mercy among Your righteous slaves."

\begin{tabular}{|c|c|c|}
\hline SN & MT System & Sample of MT output \\
\hline 1 & $\begin{array}{l}\text { Google } \\
\text { translate }\end{array}$ & $\begin{array}{l}\text { of Islam that believes that the universe, including his Creator is Allah alone with no partner and is above the heavens } \\
\text { familiar with the creation see them and hear them it is worthy of worship, }\end{array}$ \\
\hline 2 & $\begin{array}{l}\text { Bing } \\
\text { translator }\end{array}$ & $\begin{array}{l}\text { Islam that believes that this universe including creator is God alone with no partner and is above the heavens the } \\
\text { creation seen and heard them and is owed to worship, }\end{array}$ \\
\hline 3 & $\begin{array}{l}\text { Babylon } \\
\text { translation }\end{array}$ & $\begin{array}{l}\text { of Islam that believes that this universe including a Creator Is Allah alone is not a partner to the skies over the } \\
\text { beginning of the creation mentors and that a receivable of worship, }\end{array}$ \\
\hline 4 & World lingo & $\begin{array}{l}\text { From the Islam to guarantees that the universe raved including for him Creator he Allah and his border partner for } \\
\text { him and he above a alsmwa at beginning on the character sees them and hears them hears them and he the accrual } \\
\text { for the worship }\end{array}$ \\
\hline
\end{tabular}

\section{Appendix C}

\section{Sample of Output Translation of the Four Machine Translation Systems}

\section{Copyrights}

Copyright for this article is retained by the author(s), with first publication rights granted to the journal.

This is an open-access article distributed under the terms and conditions of the Creative Commons Attribution license (http://creativecommons.org/licenses/by/3.0/). 